\title{
Role and therapeutic potential of the pro-longevity factor FOXO and its regulators in neurodegenerative disease
}

\author{
Christian Neri * \\ Laboratory of Neuronal Cell Biology and Pathology, Unit 894, INSERM, Paris, France
}

\section{Edited by:}

Aleksey G. Kazantsev, Harvard

Medical School and Massachusetts

General Hospital, USA

\section{Reviewed by:}

Anthony A. Sauve, Weill Cornell

Medical College, USA

Miaozong Wu, Marshall University,

USA

Pere Puigserver, Dana-Farber Cancer Institute, USA

\section{*Correspondence:}

Christian Neri, Laboratory of Neuronal Cell Biology and Pathology, Unit 894, INSERM, 2-ter rue d'Alesia, 75014

Paris, France.

e-mail: christian.neri@inserm.fr
Studies in simple model organisms have yielded crucial insights into the genetic and molecular aspects of longevity. FOXO, which is most notable for its association with longevity, and its upstream regulators such as sirtuins have received particular attention in translational research because these genes modulate cell survival in several models of neurodegenerative diseases. There is a large amount of knowledge on the pathways that regulate FOXO activity and genes that may be regulated by FOXO. However, for the same reason that the FOXO network is a complex stress response system, its therapeutic potential to develop disease-modifying strategies requires further examination. Although the FOXO network contains druggable genes such as sirtuins and AMPK, whether they should be activated or inhibited and whether protection against the early or late phases of neuronal cell decline might require opposite therapeutic strategies remains unclear. Additionally, the mode of action of small compound molecules believed to act on FOXO network targets was questioned. This review recapitulates essential facts and questions about the promises of FOXO and its interactors in neurodegenerative disease.

Keywords: Foxo, longevity, disease

\section{INTRODUCTION}

A major challenge in neurodegenerative disease research is to identify disease-modifying strategies. Given the complexity of sporadic disease such as Alzheimer's disease (AD) or Parkinson's disease (PD), the study of inherited neurodegenerative disease is expected to shed light on the mechanisms that underlie neurodegeneration. In this respect, Huntington's disease (HD), a dominantly inherited disease with CAG expansion in the huntingtin (htt) gene and expanded polyglutamine (polyQ) tracts in the htt protein causing striatal and cortical degeneration (Walker, 2007) has become a "model neurodegenerative disease." The large number of models for HD, the knowledge on HD mechanisms (Zuccato et al., 2010) and the availability of well-characterized cohorts of HD subjects indeed provide a unique framework in which to investigate the therapeutic potential of target genes and pathways. Among the many genes that could be targeted in HD (Zuccato et al., 2010), longevity modulators, and more largely, genes which are essential to cellular homeostasis are the subject of intense research because they may directly regulate important cell survival mechanisms such as for example oxidative stress response and protein quality control. While several genes may modulate lifespan (Narasimhan et al., 2009), a limited number of genes may function to promote longevity. This is notably true for the FOXO proteins, a family of forkhead transcription factors that is conserved from Caenorhabditis Elegans (C. elegans) to mammals. FOXO factors indeed increase longevity in invertebrates, and in mammals they have a wide range of functions as further detailed below. The purpose of this review is to discuss the role of FOXO proteins and members of the FOXO network as neurodegeneration modulators.

\section{THE FOXO NETWORK}

Several signaling pathways such as the PI3K-AKT pathway, stressactivated pathways such as the MST-1 and JNK pathways, and the SIR-2 and AMPK pathways converge onto FOXO proteins to regulate a variety of biological processes which are important to development, metabolism, tumor suppression, and longevity (Calnan and Brunet, 2008). A large number of studies have indicated that, in response to external stimuli including growth factors such as insulin and insulin-like growth factor (IGF-1), nutrients, cytokines, and oxidative stress stimuli, these pathways are able to regulate the subcellular localization, DNA binding activity, transcriptional activity, and stability of these FOXO proteins. These studies have been thoroughly reviewed in excellent articles to which to refer for more details (Greer and Brunet, 2005; Calnan and Brunet, 2008; Landis and Murphy, 2010; Yen et al., 2011); a finely tuned regulatory network is emphasized in which, through a series of context-dependent post-translational modifications and interactions with co-regulators, FOXO proteins are able to integrate several types of external stimuli to regulate gene expression and modulate cell cycle arrest, apoptosis, autophagy, angiogenesis, differentiation, stress resistance, stem cell maintenance, glucogenesis, and food intake. Nutrient-sensing pathways are important upstream components of this regulatory network. Nutrient-sensing factors such as insulin/insulin-like growth factor (IGF) signaling (IIS), NAD+-dependent histone deacetylases (sirtuins/SIR-2/SIRTs), the target of rapamycin (TOR) kinase, and ribosomal S6 Kinase (TOR/S6K) pathway and the AMPK pathway may be targeted by dietary restriction to slow aging (Cabreiro and Gems, 2010; Chiacchiera and Simone, 2010). Additionally, nutrient-sensing pathways are also key regulators of FOXO activity. 
It is for example well-established that IIS modifies FOXO proteins at specific phosphorylation sites, with reduction of IIS activating FOXO, which may translate into lifespan extension in invertebrates (Calnan and Brunet, 2008). Besides IIS and modulation of FOXO phosphorylation, the SIRT1 nutrient-sensing pathway and modulation of FOXO acetylation is another important FOXO regulator. Increased sir-2.1/SIRT1 dosage in high-copy sir-2.1 transgene containing strains was indeed found to strongly increase lifespan in C. elegans, an effect that requires daf-16/FOXO (Tissenbaum and Guarente, 2001), suggesting that sirtuins could play important roles in lifespan extension. This notion has been recently challenged by additional studies in C. elegans and Drosophila melanogaster (Burnett et al., 2011; Rizki et al., 2011). These studies revealed that lifespan extension may be partially attributable to background mutations producing a dye-filling defective ("Dyf") phenotype in high-copy sir-2.1 overexpressor strains (Burnett et al., 2011; Rizki et al., 2011). While this raised the possibility that sirtuins might not be longevity-promoting factors to that extent, two independent studies indicated that lifespan extension (10-15\%) may also be achieved in low-copy sir-2.1 overexpressor strains (Rizki et al., 2011; Viswanathan and Guarente, 2011). Importantly, one of theses studies (Rizki et al., 2011) was consistent with the notion that sir-2.1 interacts with daf-16/FOXO and its co-factors such as 14-3-3 proteins in modulating lifespan (Berdichevsky et al., 2006). Furthermore, background mutations were not responsible for the strong level of neuroprotection achieved against mutant polyQs by sir- 2.1 overexpression (Burnett et al., 2011). Thus, while additional investigation will be needed to determine to which extent sirtuins may promote lifespan extension, sirtuins stand as important longevity factors that are relevant to neuronal protection in neurodegenerative disease and other protective effects in metabolic disease (Kim et al., 2007; Baur et al., 2010; Burgess, 2011; Jeong et al., 2011; Jiang et al., 2011). One may wonder why mutations producing a Dyf phenotype were found in sir-2.1 overexpressor strains despite the care made by the $C$. elegans community with distributing mutants after multiple outcrosses. The answer might come from studies made with the search for mutants resistant to avermectin (Rand and Johnson, 1995), an antiparasitic drug. Many low-level ivermectin resistance mutations in che, osm, and $d y f$ genes may produce defects in the amphid sensilla, low-level ivermectin resistance is common in C. elegans ( 1 in 5000 eggs in the absence of mutagenesis) and the ivermectin resistance allele frequency in wild nematode populations may be as high as $1 \%$ (C. D. Johnson, personal communication). Additionally, mutations that cause defects in sensory cilia genes may also extend longevity (Apfeld and Kenyon, 1999). The $d y f$ mutations may thus occur at relatively high rates, which calls for the regular assessment of C. elegans mutants for dye-filling defects in studies of longevity.

In addition to be regulated by kinases and deacetylases, FOXO activity is regulated by ubiquitin complex members such as Skp2, a protein that promotes FOXO1 degradation (Huang et al., 2005), and by co-factors such as $\beta$-catenin, a protein that binds to FOXO3a and regulates its transcriptional activity in response to oxidative stress (Essers et al., 2005). The FOXO proteins may compete with the canonical Wnt effector T cell factor (TCF) for binding to $\beta$-catenin (Hoogeboom et al., 2008), which further highlighted the importance of $\beta$-catenin in the regulation of FOXO activity. While FOXO proteins may act together with other transcription factors to regulate gene expression (Landis and Murphy, 2010), they stand at the center of a large network of upstream regulators, co-factors, and downstream targets (Figure 1) which are important for cell homeostasis. Interestingly, studies based on chromatin immunoprecipitation (Oh et al., 2006; Schuster et al., 2010), gene expression profiling in C. elegans (McElwee et al., 2003; Murphy et al., 2003) and mouse neural stem cells (NSCs; Paik et al., 2009; Renault et al., 2009), and other approaches (Lee et al., 2003; Yu et al., 2008) highlighted thousands of putative FOXO-regulated genes (Jensen et al., 2006; Murphy, 2006). These results open the avenue to a better understanding of FOXO activity in regulating downstream mechanisms in specific contexts. Given that FOXO proteins act in specific cells and tissues to execute different outputs (Landis and Murphy, 2010), it is anticipated that specific transcriptional targets may be engaged into different FOXO-mediated responses. Gene expression studies performed in either C. elegans nematodes (McElwee et al., 2003; Murphy et al., 2003) or mouse NSCs (Lee et al., 2003; Yu et al., 2008) emphasized a small number of FOXO-regulated genes across species and biological conditions (Table 1). Although poor overlap may be partially attributable to differences in the species and/or methods used for gene expression profiling, these studies suggest that FOXO proteins indeed regulate specific targets in different contexts. In addition to being important for stem cell homeostasis and adult longevity, FOXO factors are involved in development and cell differentiation (Kitamura et al., 2007; Demontis and Perrimon, 2009; Yuan et al., 2009; de la Torre-Ubieta et al., 2010; Kerdiles et al., 2010; Schuff et al., 2010), and they may be important to promote adult neurogenesis as suggested by studies in Drosophila melanogaster (Siegrist et al., 2010). Thus, FOXO factors may be essential to cell response homeostasis during the entire lifetime of a living organism. As such, it is not surprising that FOXO proteins and their main regulators such as sirtuins were implicated in the protection against age-associated diseases such as cancer, diabetes, cardiovascular disease, and neurodegeneration (Dansen and Burgering, 2008; Chiacchiera and Simone, 2010; Herranz and Serrano, 2010).

\section{THE SIR-2/FOXO PATHWAY AND ITS ROLE IN DEGENERATIVE DISEASE}

For the same reason that pathways converging onto FOXO are important to cell survival and longevity, they are of particular interest to explore how to promote neuron or muscle cell survival in degenerative disease. Over the past years, accumulating evidence on the therapeutic potential of FOXO and its interactors for age-related diseases has been obtained. Perhaps the first observation suggesting that longevity-promoting factors might be able to modulate the toxicity of degenerative disease proteins was obtained in the nematode $C$. elegans. In transgenic nematodes expressing polyQ tracts in body wall muscle cells, reducing IIS by use of age-1/PI3K loss-of-function (LOF) mutants decreased the toxicity associated to expanded polyQs, and this effect was dependent on daf-16/FOXO (Morley et al., 2002). Direct evidence for longevity-promoting factors such as SIR-2 and FOXO to protect diseased neurons at an early stage of cellular decline was obtained by using a $C$. elegans model of HD pathogenesis 
Table 1 | Putative FOXO targets emphasized by microarray analysis in either $C$. elegans or mouse NSCs, or both.

\begin{tabular}{|c|c|c|c|c|c|}
\hline \multirow[t]{2}{*}{ Mouse gene name } & \multirow[t]{2}{*}{ Worm ORF ID } & \multicolumn{2}{|c|}{ C. elegans } & \multicolumn{2}{|c|}{ Mouse NSCs } \\
\hline & & $\begin{array}{l}\text { Murphy et al. } \\
(2003)\end{array}$ & $\begin{array}{l}\text { McElwee et al. } \\
(2003)^{*}\end{array}$ & $\begin{array}{l}\text { Renault et al. } \\
\text { (2009) }\end{array}$ & $\begin{array}{l}\text { Paik et al. } \\
(2009)\end{array}$ \\
\hline Cav1 & T13F2.8 & $U$ & - & $\mathrm{D}$ & - \\
\hline Mxd1 & R03E9.1 & $\mathrm{D}$ & - & $\mathrm{D}$ & $\mathrm{D}$ \\
\hline Sod2 & C08A9.1 & $\mathrm{D}$ & U & - & - \\
\hline RIKEN cDNA 6230409E13 & C54D10.1 & $\mathrm{D}$ & U & - & - \\
\hline Nxn12 & F17B5.1 & $\mathrm{D}$ & $U$ & - & - \\
\hline Dgat2 & K07B1.4 & $\mathrm{D}$ & $U$ & - & - \\
\hline Birc5 & C50B8.2 & - & $U$ & - & $U$ \\
\hline Myo1b & F29D10.4 & - & $U$ & - & $U$ \\
\hline Slc25a5 & W02D3.6 & - & $U$ & - & $u$ \\
\hline Gspt1 & H19N07.1 & $U$ & - & - & $U$ \\
\hline Jag1 & R107.8 & $U$ & - & - & $U$ \\
\hline Lta4h & ZC416.6 & $U$ & - & - & $U$ \\
\hline Mapk8 & B0478.1 & $U$ & - & - & $u$ \\
\hline Pcna & W03D2.4 & $U$ & - & - & $U$ \\
\hline Psmc5 & Y49E10.1 & $U$ & - & - & $U$ \\
\hline Bphl & K01A2.5 & U & - & - & $\mathrm{D}$ \\
\hline Dpyd & C25F6.3 & U & - & - & $\mathrm{D}$ \\
\hline Slc15a2 & K04E7.2 & $U$ & - & - & $\mathrm{D}$ \\
\hline Comtd1 & Y40B10A.2, Y40B10A.6 & $\mathrm{D}$ & - & - & $U$ \\
\hline Gnb5 & F52A8.2 & $\mathrm{D}$ & - & - & $U$ \\
\hline Fads2 & W08D2.4 & $\mathrm{D}$ & - & - & $\mathrm{D}$ \\
\hline Ppap2c & T28D9.3 & $\mathrm{D}$ & - & - & $\mathrm{D}$ \\
\hline Syt11 & $\mathrm{T} 23 \mathrm{H} 2.2$ & $D$ & - & - & $D$ \\
\hline
\end{tabular}

U, up-regulated; D, down-regulated. *The promoter of these dysregulated genes also contain FOXO binding sites (McElwee et al., 2003). -, Not dysregulated. This table is based on the simple comparison of four studies performed in either C. elegans (McElwee et al., 2003; Murphy et al., 2003) or mouse NSCs (Lee et al., 2003; Yu et al., 2008).

in which expression of polyQ-expanded $\mathrm{N}$-terminal huntingtin in touch receptor neurons induced neuronal dysfunction (lossglu of response to light touch) in the absence of cell death (Parker et al., 2001). In these animals, increased sir-2.1/SIRT1 dosage protects from expanded polyQs, with reduction of axonal dystrophy, whereas sir-2.1 LOF aggravates expanded polyQ toxicity (Parker et al., 2005). This neuroprotective effect is not due to unrelated mutations (i.e., mutations producing a Dyf phenotype) in the high-copy sir-2.1 transgene containing strains as neuroprotection was observed to the same extent in non-Dyf, sir-2.1 overexpressors (Burnett et al., 2011). Additionally, sir-2.1 neuroprotection in this model requires daf-16/FOXO (Parker et al., 2005), emphasizing a role for the SIR-2.1/DAF-16 pathway. This suggested that raising the activity of the SIRT1 pathway may protect from mutant huntingtin in mammalian models of HD. This notion was supported by other C. elegans-based studies (Bates et al., 2006), and consistent with the protective effects of situins in common neurological disorders. However, studies in Drosophila melanogaster suggested that Sir-2 knockdown protects from neurodegeneration as induced by $\mathrm{N}$-terminal htt expression in the compound eye, with no effect of overexpressing Sir-2 (Pallos et al., 2008). These results suggested that the role of Sir- 2 in 


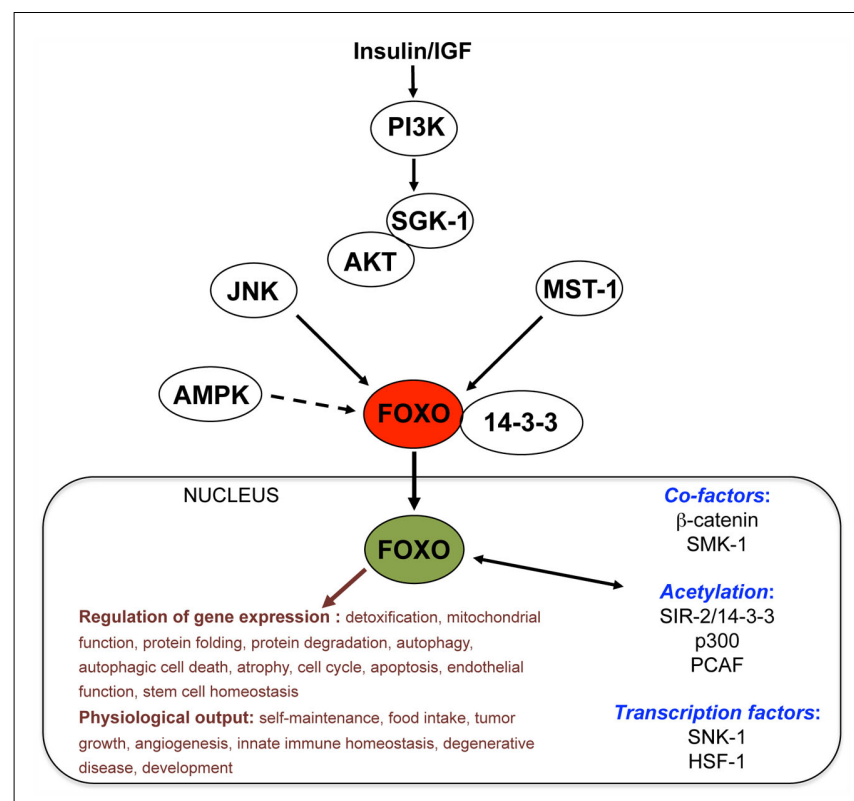

FIGURE 1 | Simplified view of the FOXO network. This diagram shows signaling pathways well-established (straight arrows) or hypothesized (dashed arrow) to converge onto FOXO. The list of target gene classes and physiological outputs is not exhaustive. mutant polyglutamine neurons may be complex. Nematodes with expanded polyQ expression in touch receptor neurons recapitulate neuron dysfunction before cell death and pointed to the FOXO-dependent effect of homozygous loss of Sir-2 (Parker et al., 2005). Flies with expanded polyQ expression in the eye show neurodegeneration and pointed to an effect of heterozygous loss of Sir-2 that may be unrelated to longevity (Pallos et al., 2008). While these differences illustrated the importance of parameters such as the severity of pathology, type of gene dosage and identity of downstream effectors when pursuing therapeutic targets, two independent studies recently reported that SIRT1 is neuroprotective in several mouse models of HD (Jeong et al., 2011;jiang et al., 2011). Interestingly, FOXO3a may be involved in the neuroprotective effects of SIRT1 and the reduction of SIRT1 exacerbates mutant huntingtin toxicity (Jiang et al., 2011), which should help settle the question. Besides SIRT1 manipulation, SIRT2 inhibition may also be neuroprotective in diseases such as HD (Luthi-Carter et al., 2010) and PD (Outeiro et al., 2007). As suggested by the function of SIRT2, a microtubule deacetylase, and by the effects of SIRT2 inhibitors in models of HD (Luthi-Carter et al., 2010), the mechanisms for neuroprotection by SIRT2 inhibition may differ from those elicited by SIRT1 manipulation. However, FOXO proteins are deacetylated by SIRT2 (Zhao et al., 2010; Wang et al., 2011), raising the possibility that neuroprotection by SIRT2 inhibition might involve FOXO activity.

Consistent with the protection of mutant polyQ neurons by SIR-2/SIRT1, neuroprotection by sir-2.1 overexpression was also demonstrated in C. elegans nematodes expressing octa-repeat expanded PrP in mechanosensory neurons (Bizat et al., 2010).
In these animals, the neuroprotective effect of sir-2.1 was unrelated to an effect on the conformation of mutant PrP since sir-2.1 overexpression did not reduce proteinase K-resistant PrP levels (Bizat et al., 2010). Several studies have further extended the neuroprotective activity of SIR-2/SIRT1 and FOXO in models of neurodegenerative diseases. Sirtuin SIRT1 is up-regulated in mouse models of AD and amyotrophic lateral sclerosis (ALS), and SIRT1 is protective in cell-based models of ALS and AD/tauopathies (Kim et al., 2007), providing evidence for SIRT1 to protect diseased neurons. Neurite outgrowth, cell viability and tolerance to degeneration induced by $\mathrm{A} \beta(1-42)$ oligomers are promoted in primary neurons from mice with neuron-specific SIRT1 overexpression (Guo et al., 2011), further supporting the notion that SIRT1 is able to protect diseased neurons. In C. elegans nematodes expressing $A \beta(1-42)$ in body wall muscle cells (Link et al., 2003), daf-16/FOXO and heat shock factor 1 (hsf-1) cooperate to regulate a two-step cell survival response involving disaggregation/aggregation (Cohen et al., 2006). Consistently, in a mouse model of $\mathrm{AD}$ (APPswe/Presenilin1- $\triangle \mathrm{E} 9$ mice), genetically reducing IGF signaling protects from Alzheimer's-like disease symptoms (Cohen et al., 2009). Finally, it is notable that allelic variation in FOXO3A was associated with the ability to be long-lived as suggested by several association studies in populations of centenarians (Willcox et al., 2008; Anselmi et al., 2009; Flachsbart et al., 2009; Li et al., 2009; Soerensen et al., 2010; Kleindorp et al., 2011).

While the SIR-2.1/DAF-16 pathway may protect mutant polyQ neurons, it has opposite effects in a $C$. elegans model of oculopharyngeal muscular dystrophy (OPMD), a late-onset disease caused by expanded polyalanines in the PABPN1 protein (Catoire et al., 2008). In C. elegans transgenics expressing human PABPN1 in body wall muscle cells, sir-2.1 overexpression indeed aggravates muscle cell decline and abnormal motility caused by mutant PABPN1 expression, whereas sir-2.1 LOF is protective in a daf16/FOXO-dependent manner (Catoire et al., 2008). These observations suggested that the status of FOXO activity in mutant polyQ neurons is different from that of mutant polyAla muscle cells. These results also suggested that SIRT1 inhibitors have therapeutic potential in OPMD as further illustrated by pharmacological studies in PABPN1 nematodes (Pasco et al., 2010).

\section{MODULATION OF NEURODEGENERATIVE DISEASE TARGETS IN THE FOXO NETWORK}

Over the past years, studies of SIRT1/FOXO activity in models of disease have the search for SIRT1 activators and inhibitors with clinical potential. While the aim of this review is not to cover drug discovery and clinical development in the field of sirtuin research, it is notable that the mechanisms of action of SIRT1-activating compounds (STACs) have been the subject of debate. This applies to resveratrol, a plant polyphenol that has a broad range of beneficial activities on health span (Wood et al., 2004; Baur et al., 2006; Fulda and Debatin, 2006; Lagouge et al., 2006), is neuroprotective in several models of neurodegenerative diseases (Parker et al., 2005; Kim et al., 2007; Bizat et al., 2010; Richard et al., 2011) and has attracted a lot of attention as a potential drug (Patel et al., 2011). Resveratrol was initially thought to primarily activate SIRT1 (Howitz et al., 2003). It is now thought that resveratrol has multiple mechanisms of action 
(Harikumar and Aggarwal, 2008). Resveratrol might not always require SIRT1 for activity against expanded polyQs (Parker et al., 2005; Pallos et al., 2008), and it could activate AMPK (Dasgupta and Milbrandt, 2007) and the peroxisome proliferator-activated receptor coactivator-1alpha (PGC-1alpha; Lagouge et al., 2006) and inhibits PI3K (Frojdo et al., 2007). This promoted the search for selective SIRT1 activators (Milne et al., 2007), which led to find that they may act as caloric restriction mimetics (Smith et al., 2009). Although STACs hold promises for the treatment of ageassociated diseases, their mechanisms of action and therapeutic potential was controversial. A positive aspect of this controversy was to emphasize the need for more robust acetylation assays and in-depth assessment of the promiscuity of STACs. Studies in the field indeed raised the possibility that complex formation between STACs and fluorophore-labeled substrate peptides plays a role in the activation of SIRT1 (Pacholec et al., 2010), whereas other studies subsequently showed that STACs are able to activate unlabelled peptides, suggesting that STACs may interact directly with SIRT1 and activate SIRT1-catalyzed deacetylation through an allosteric mechanism (Dai et al., 2010). While the debate regarding STAC activities might continue, progress appears to be made with harnessing the therapeutical potential of STACs in metabolic disorder. The development of SRT501 (a formulation of resveratrol) for diabetes was terminated whereas new STACs structurally distinct from resveratrol such as SRT2104 are being evaluated (Huber and Superti-Furga, 2011). Further developments are highly awaited to know if these molecules may provide clinically safe drugs for neurodegenerative disease. The situation has been less controversial in regard to sirtuin inhibition as SIRT inhibitors with good selectivity for either SIRT1 (e.g., EX-527) or SIRT2 (e.g., AGK2) have been identified (Mai et al., 2009; Luthi-Carter et al., 2010; Pasco et al., 2010; Taylor et al., 2011). Compared to the mechanisms for neuroprotection by SIRT1 activation, the biology of neuroprotection by SIRT inhibition is not understood to that extent. In any case, progress with identifying the neuronal function of sirtuins (Dietrich et al., 2010; Ramadori et al., 2010, 2011; Guo et al., 2011; Maxwell et al., 2011) and targets modulated by these enzymes (Wang et al., 2007, 2011; Li et al., 2008; Zhao et al., 2010) will help define the therapeutic potential of SIRT inhibitors in neurodegenerative disease.

Besides sirtuins, another neurodegenerative disease target of interest in the FOXO network is AMPK, a key regulator of cellular metabolism that is activated by a decrease in energy levels (Steinberg and Kemp, 2009). Interestingly, an AMPK-FOXO3a pathway might be involved in shifting the cell from energy consumption to energy production in cancer-specific metabolism (Chiacchiera and Simone, 2009, 2010; Chiacchiera et al., 2009), a mechanism also emphasized by the ability of an AMPK-FOXO pathway to mediate longevity in response to dietary restriction in C. elegans (Greer et al., 2007). Since there is multiple evidence for mitochondrial and metabolic defects in neurodegenerative diseases such as HD (Zuccato et al., 2010), it is tempting to speculate that one important mechanism to compensate for metabolic defect in HD could be the use of an AMPK-FOXO pathway. If true, then AMPK activation might protect against the early phases of the pathogenic process in neurodegenerative disease. However, the AMPK-FOXO pathway may end up activating autophagic cell death upon prolonged metabolic stress in cancer cells (Chiacchiera and Simone, 2009, 2010; Chiacchiera et al., 2009), raising the possibility that AMPK-FOXO might contribute to neurodegeneration, which might be particularly harmful during the late phases of the pathogenic process in neurodegenerative disease. Studies in models of neurodegeneration reflect the complexity of the AMPKmediated regulation of cell survival. Although the AMPK activator metformin protects primary cortical neurons from etoposideinduced cell death (El-Mir et al., 2008) and ameliorates survival and motor defects in R6/2 transgenic mice expressing mutant $\mathrm{N}$ terminal huntingtin (Ma et al., 2007), other studies suggested that metformin may increase the generation of $A \beta$ peptides via BACE1 upregulation in cellular models (Chen et al., 2009). In regard to AMPK activity in neurons, conflicting observations have been made. Because neurons do not efficiently store nutrients, AMPK may be essential to neuron activity and survival, suggesting that AMPK activation might protect neurons from metabolic stress in neurodegenerative disease. However, AMPK appears to be abnormally activated in pre-tangle and tangle neurons in AD and other tauopathies (Vingtdeux et al., 2011). Additionally, there is nuclear translocation of the AMPK-alphal subunit in the striatum of postmortem HD brains and mice with a fast-developing HD pathology (Ju et al., 2011). While this suggests that AMPK might have a pathological role in HD, studies of AMPK in additional models of HD are warranted considering the pro-survival role of AMPK in neurons and diversity of pathology in HD mice. Collectively, these data highlight the need for more studies of the modulation of AMPK activity toward specific targets in models that recapitulate the early/mild versus late/severe components of the pathogenic process in neurodegenerative disease. This will allow the potential of AMPK-targeted therapy in neurodegenerative disease treatment to be clarified. It will also be important to identify the small compound molecules that might be used in this respect (Steinberg and Kemp, 2009).

\section{PERSPECTIVES}

There is accumulating evidence on the protective role of FOXO proteins and their interactors in response to cellular stress in agerelated diseases. One of the current challenges is to identify the downstream mechanisms by which FOXO factors are essential to neuron survival in neurodegenerative disease. Given the complex regulation of gene expression by FOXO proteins and their interactors, it will be important to investigate how FOXO transcriptional targets may be involved in the regulation of survival responses in specific neurodegenerative diseases and to evaluate whether this may be relevant to other neurodegenerative diseases. Another challenge is to assess whether the pathways that regulate FOXO transcriptional activity should be activated or inhibited to modify the pathogenic process in neurodegenerative disease, and whether the same approach should be used against the early/mild versus late/severe phases of the pathology. Sustaining neuron survival at an early phase of the pathology and reducing neuronal cell death in late disease might require the same FOXO activity to be modulated in opposing fashions. This possibility is supported by the ability of FOXO proteins and their interactors to orchestrate two-step responses in which the net outcome may be cell survival (Cohen et al., 2006) or cell demise (Chiacchiera and Simone, 
2010) in response to prolonged stress. Thus, while several questions remain unanswered, future and exciting developments are expected to shed light on the importance and therapeutic potential of the FOXO network in neurodegenerative disease.

\section{REFERENCES}

Anselmi, C. V., Malovini, A., Roncarati, R., Novelli, V., Villa, F., Condorelli, G., Bellazzi, R., and Puca, A. A. (2009). Association of the FOXO3A locus with extreme longevity in a southern Italian centenarian study. Rejuvenation Res. 12, 95-104.

Apfeld, J., and Kenyon, C. (1999). Regulation of lifespan by sensory perception in Caenorhabditis elegans. Nature 402, 804-809.

Bates, E. A., Victor, M., Jones, A. K., Shi, Y., and Hart, A. C. (2006). Differential contributions of Caenorhabditis elegans histone deacetylases to huntingtin polyglutamine toxicity. $J$. Neurosci. 26, 2830-2838.

Baur, J. A., Chen, D., Chini, E. N., Chua, K., Cohen, H. Y., De Cabo, R., Deng, C., Dimmeler, S., Gius, D., Guarente, L. P., Helfand, S. L., Imai, S., Itoh, H., Kadowaki, T., Koya, D., Leeuwenburgh, C., Mcburney, M., Nabeshima, Y., Neri, C., Oberdoerffer, P., Pestell, R. G., Rogina, B., Sadoshima, J., Sartorelli, V., Serrano, M., Sinclair, D. A., Steegborn, C., Tatar, M., Tissenbaum, H. A., Tong, Q., Tsubota, K., Vaquero, A., and Verdin, E. (2010). Dietary restriction: standing up for sirtuins. Science 329, 1012-1013.

Baur, J. A., Pearson, K. J., Price, N. L., Jamieson, H. A., Lerin, C., Kalra, A., Prabhu, V. V., Allard, J. S., LopezLluch, G., Lewis, K., Pistell, P. J., Poosala, S., Becker, K. G., Boss, O., Gwinn, D., Wang, M., Ramaswamy, S., Fishbein, K. W., Spencer, R. G., Lakatta, E. G., Le Couteur, D., Shaw, R. J., Navas, P., Puigserver, P., Ingram, D. K., De Cabo, R., and Sinclair, D. A. (2006). Resveratrol improves health and survival of mice on a highcalorie diet. Nature 444, 337-342.

Berdichevsky, A., Viswanathan, M., Horvitz, H. R., and Guarente, L. (2006). C. elegans SIR-2.1 interacts with 14-3-3 proteins to activate DAF-16 and extend life span. Cell 125, 1165-1177.

Bizat, N., Peyrin, J. M., Haik, S., Cochois, V., Beaudry, P., Laplanche, J. L., and Neri, C. (2010). Neuron dysfunction is induced by prion protein with an insertional mutation via a Fyn kinase and reversed by sirtuin activation in Caenorhabditis elegans. J. Neurosci. 30, 5394-5403.

Burgess, D. J. (2011). Model organisms: the dangers lurking in the genetic background. Nat. Rev. Genet. 12 742.

Burnett, C., Valentini, S., Cabreiro, C., Goss, M., Somogyvári, M., Piper, M., Hoddinott, M., Sutphin, G., Leko, V., Mcelwee, J., Vazquez-Manrique, R., Orfila, A., Ackerman, D., Au, C., Vinti, G., Riesen, M., Howard, K., Neri, C., Bedalov, A., Kaeberlein, M., Soti, C., Partridge, L., and Gems, D. (2011). Absence of effects of Sir2 overexpression on lifespan in C. ele482-485.

Cabreiro, F., and Gems, D. (2010). Treating aging: progress toward dietary restriction mimetics. $F 1000 \mathrm{Biol}$. Rep. 2, 76.

Calnan, D. R., and Brunet, A. (2008). The FoxO code. Oncogene 27, 2276-2288.

Catoire, H., Pasco, M. Y., Abu-Baker, A., Holbert, S., Tourette, C., Brais, B., Rouleau, G. A., Parker, J. A., and Neri, C. (2008). Sirtuin inhibition protects from the polyalanine muscular dystrophy protein PABPN1. Hum. Mol. Genet. 17, 2108-2117.

Chen, Y., Zhou, K., Wang, R., Liu, Y., Kwak, Y. D., Ma, T., Thompson, R. C., Zhao, Y., Smith, L., Gasparini, L., Luo, Z., Xu, H., and Liao, F. F. (2009). Antidiabetic drug metformin (GlucophageR) increases biogenesis of Alzheimer's amyloid peptides via up-regulating BACE1 transcription. Proc. Natl. Acad. Sci. U.S.A. 106, 3907-3912.

Chiacchiera, F., Matrone, A., Ferrari, E., Ingravallo, G., Lo Sasso, G., Murzilli, S., Petruzzelli, M., Salvatore, L., Moschetta, A., and Simone, C. (2009). p38alpha blockade inhibits colorectal cancer growth in vivo by inducing a switch from HIFlalpha- to FoxO-dependent transcription. Cell Death Differ. 16, 1203-1214.

Chiacchiera, F., and Simone, C. (2009). Inhibition of p38alpha unveils an AMPK-FoxO3A axis linking autophagy to cancer-specific metabolism. Autophagy 5, 1030-1033.

Chiacchiera, F., and Simone, C. (2010). The AMPK-FoxO3A axis as a target for cancer treatment. Cell Cycle 9, 1091-1096.

Cohen, E., Bieschke, J., Perciavalle, R. M., Kelly, J. W., and Dillin, A. (2006). Opposing activities protect against age-onset proteotoxicity. $\mathrm{Sci}$ ence $313,1604-1610$. gans and Drosophila. Nature 477,

\section{ACKNOWLEDGMENTS}

The comparison of previously reported microarray studies of FOXO targets was performed by Frédéric Parmentier and François-Xavier Lejeune.

Cohen, E., Paulsson, J. F., Blinder, P., Burstyn-Cohen, T., Du, D., Estepa, G., Adame, A., Pham, H. M., Holzenberger, M., Kelly, J. W., Masliah, E. and Dillin, A. (2009). Reduced IGF1 signaling delays age-associated proteotoxicity in mice. Cell 139, 1157-1169.

Dai, H., Kustigian, L., Carney, D. Case, A., Considine, T., Hubbard, B. P., Perni, R. B., Riera, T. V., Szczepankiewicz, B., Vlasuk, G. P., and Stein, R. L. (2010). SIRT1 activation by small molecules: kinetic and biophysical evidence for direct interaction of enzyme and activator. $J$. Biol. Chem. 285, 32695-32703.

Dansen, T. B., and Burgering, B. M. (2008). Unravelling the tumorsuppressive functions of FOXO proteins. Trends Cell Biol. 18, 421-429.

Dasgupta, B., and Milbrandt, J. (2007). Resveratrol stimulates AMP kinase activity in neurons. Proc. Natl. Acad. Sci. U.S.A. 104, 7217-7222.

de la Torre-Ubieta, L., Gaudilliere, B. Yang, Y., Ikeuchi, Y., Yamada, T., Dibacco, S., Stegmuller, J., Schuller, U., Salih, D. A., Rowitch, D., Brunet, A., and Bonni, A. (2010). A FOXOPak1 transcriptional pathway controls neuronal polarity. Genes Dev. 24, 799-813.

Demontis, F., and Perrimon, N. (2009). Integration of insulin receptor/Foxo signaling and dMyc activity during muscle growth regulates body size in Drosophila. Development 136, 983-993.

Dietrich, M. O., Antunes, C., Geliang, G., Liu, Z. W., Borok, E., Nie, Y., Xu, A. W., Souza, D. O., Gao, Q. Diano, S., Gao, X. B., and Horvath, T. L. (2010). Agrp neurons mediate Sirtl's action on the melanocortin system and energy balance: roles for Sirtl in neuronal firing and synaptic plasticity. J. Neurosci. 30, 11815-11825.

El-Mir, M. Y., Detaille, D., R-Villanueva, G., Delgado-Esteban, M., Guigas, B. Attia, S., Fontaine, E., Almeida, A. and Leverve, X. (2008). Neuroprotective role of antidiabetic drug metformin against apoptotic cell death in primary cortical neurons. J. Mol. Neurosci. 34, 77-87.

Essers, M. A., De Vries-Smits, L. M., Barker, N., Polderman, P. E., Burgering, B. M., and Korswagen, $\mathrm{H}$. C. (2005). Functional interaction between beta-catenin and FOXO in oxidative stress signaling. Science 308, 1181-1184.

Flachsbart, F., Caliebe, A., Kleindorp, R. Blanche, H., Von Eller-Eberstein, H., Nikolaus, S., Schreiber, S., and Nebel, A. (2009). Association of FOXO3A variation with human longevity confirmed in German centenarians. Proc. Natl. Acad. Sci. U.S.A. 106, 2700-2705.

Frojdo, S., Cozzone, D., Vidal, H., and Pirola, L. (2007). Resveratrol is a inhibitor. Biochem. J. 406, 511-518.

Fulda, S., and Debatin, K. M. (2006). Resveratrol modulation of signal transduction in apoptosis and cell survival: a mini-review. Cancer Detect. Prev. 30, 217-223.

Greer, E. L., and Brunet, A. (2005). FOXO transcription factors at the interface between longevity and tumor suppression. Oncogene 24, 7410-7425.

Greer, E. L., Dowlatshahi, D., Banko, M. R., Villen, J., Hoang, K., Blanchard, D., Gygi, S. P., and Brunet, A. (2007). An AMPK-FOXO pathway mediates longevity induced by a novel method of dietary restriction in C. elegans. Curr. Biol. 17, 1646-1656.

Guo, W., Qian, L., Zhang, J., Zhang, W., Morrison, A., Hayes, P., Wilson S., Chen, T., and Zhao, J. (2011). Sirtl overexpression in neurons promotes neurite outgrowth and cell survival through inhibition of the mTOR signaling. J. Neurosci. Res. 89, 1723-1736.

Harikumar, K. B., and Aggarwal, B. B. (2008). Resveratrol: a multitargeted agent for age-associated chronic diseases. Cell Cycle 7, 1020-1035.

Herranz, D., and Serrano, M. (2010). SIRT1: recent lessons from mouse models. Nat. Rev. Cancer 10, 819-823.

Hoogeboom, D., Essers, M. A., Polderman, P. E., Voets, E., Smits, L. M., and Burgering, B. M. (2008). Interaction of FOXO with beta-catenin inhibits beta-catenin/T cell factor activity. J. Biol. Chem. 283, 9224-9230.

Howitz, K. T., Bitterman, K. J., Cohen, H. Y., Lamming, D. W., Lavu, S., Wood, J. G., Zipkin, R. E., Chung, P., Kisielewski, A., Zhang, L. L., Scherer, B., and Sinclair, D. A. (2003). Small molecule activators of sirtuins extend Saccharomyces cerevisiae lifespan. Nature 425, 191-196. class IA phosphoinositide 3-kinase 
Huang, H., Regan, K. M., Wang, F., Wang, D., Smith, D. I., Van Deursen, J. M., and Tindall, D. J. (2005). Skp2 inhibits FOXO1 in tumor suppression through ubiquitin-mediated degradation. Proc. Natl. Acad. Sci. U.S.A. 102, 1649-1654

Huber, K., and Superti-Furga, G. (2011). After the grape rush: sirtuins as epigenetic drug targets in neurodegenerative disorders. Bioorg. Med. Chem. 19, 3616-3624.

Jensen, V. L., Gallo, M., and Riddle, D. L. (2006). Targets of DAF-16 involved in Caenorhabditis elegans adult longevity and dauer formation. Exp. Gerontol. 41, 922-927.

Jeong, H., Cohen, D. E., Cui, L., Supinski, A., Savas, J. N., Mazzulli, J. R., Yates, J. R. III, Bordone, L., Guarente, L., and Krainc, D. (2011). Sirtl mediates neuroprotection from mutant huntingtin by activation of the TORC1 and CREB transcriptional pathway. Nat. Med. 18, 159-165.

Jiang, M., Wang, J., Fu, J., Du, L., Jeong, H., West, T., Xiang, L., Peng, Q., Hou, Z., Cai, H., Seredenina, T., Arbez, N., Zhu, S., Sommers, K., Qian, J., Zhang, J., Mori, S., Yang, X. W., Tamashiro, K. L., Aja, S., Moran, T. H., Luthi-Carter, R., Martin, B., Maudsley, S., Mattson, M. P., Cichewicz, R. H., Ross, C. A., Holtzman, D. M., Krainc, D., and Duan, W. (2011). Neuroprotective role of Sirt1 in mammalian models of Huntington's disease through activation of multiple Sirt1 targets. Nat. Med. 18, 153-158.

Ju, T. C., Chen, H. M., Lin, J. T., Chang, C. P., Chang, W. C., Kang, J. J., Sun, C. P., Tao, M. H., Tu, P. H., Chang, C., Dickson, D. W., and Chern, Y. (2011). Nuclear translocation of AMPK-alphal potentiates striatal neurodegeneration in Huntington's disease. J. Cell Biol. 194, 209-227.

Kerdiles, Y. M., Stone, E. L., Beisner, D. R., Mcgargill, M. A., Ch'En, I. L., Stockmann, C., Katayama, C. D., and Hedrick, S. M. (2010). Foxo transcription factors control regulatory $\mathrm{T}$ cell development and function. Immunity 33, 890-904.

Kim, D., Nguyen, M. D., Dobbin, M. M., Fischer, A., Sananbenesi, F., Rodgers, J. T., Delalle, I., Baur, J. A., Sui, G., Armour, S. M., Puigserver, P., Sinclair, D. A., and Tsai, L. H. (2007). SIRT1 deacetylase protects against neurodegeneration in models for Alzheimer's disease and amyotrophic lateral sclerosis. EMBO J. 26, 3169-3179.

Kitamura, T., Kitamura, Y. I., Funahashi, Y., Shawber, C. J., Castrillon, D. H.,
Kollipara, R., Depinho, R. A., Kitajewski, J., and Accili, D. (2007). A Foxo/Notch pathway controls myogenic differentiation and fiber type specification. J. Clin. Invest. 117, 2477-2485.

Kleindorp, R., Flachsbart, F., Puca, A. A., Malovini, A., Schreiber, S. and Nebel, A. (2011). Candidate gene study of FOXO1, FOXO4, and FOXO6 reveals no association with human longevity in Germans. Aging Cell 10, 622-628.

Lagouge, M., Argmann, C., GerhartHines, Z., Meziane, H., Lerin, C. Daussin, F., Messadeq, N., Milne, J., Lambert, P., Elliott, P., Geny, B., Laakso, M., Puigserver, P., and Auwerx, J. (2006). Resveratrol improves mitochondrial function and protects against metabolic disease by activating SIRT1 and PGC-1alpha. Cell 127, 1109-1122.

Landis, J. N., and Murphy, C. T. (2010). Integration of diverse inputs in the regulation of Caenorhabditis elegans DAF-16/FOXO. Dev. Dyn. 239, 1405-1412.

Lee, S. S., Kennedy, S., Tolonen, A. C., and Ruvkun, G. (2003). DAF-16 target genes that control C. elegans lifespan and metabolism. Science 300, 644-647.

Li, Y., Wang, W. J., Cao, H., Lu, J., Wu, C., Hu, F. Y., Guo, J., Zhao, L., Yang, F., Zhang, Y. X., Li, W., Zheng, G. Y., Cui, H., Chen, X., Zhu, Z., He, H., Dong, B., Mo, X., Zeng, Y., and Tian, X. L. (2009). Genetic association of FOXO1A and FOXO3A with longevity trait in Han Chinese populations. Hum. Mol. Genet. 18, 4897-4904.

Li, Y., Xu, W., Mcburney, M. W., and Longo, V. D. (2008). SirT1 inhibition reduces IGF-I/IRS-2/Ras/ERK1/2 signaling and protects neurons. Cell Metab. 8, 38-48.

Link, C. D., Taft, A., Kapulkin, V., Duke, K., Kim, S., Fei, Q., Wood, D. E., and Sahagan, B. G. (2003). Gene expression analysis in a transgenic Caenorhabditis elegans Alzheimer's disease model. Neurobiol. Aging 24, 397-413.

Luthi-Carter, R., Taylor, D. M., Pallos, J., Lambert, E., Amore, A., Parker, A., Moffitt, H., Smith, D. L., Runne, H., Gokce, O., Kuhn, A., Xiang, Z., Maxwell, M. M., Reeves, S. A., Bates, G. P., Neri, C., Thompson, L. M., Marsh, J. L., and Kazantsev, A. G. (2010). SIRT2 inhibition achieves neuroprotection by decreasing sterol biosynthesis. Proc. Natl. Acad. Sci. U.S.A. 107, 7927-7932.

Ma, T. C., Buescher, J. L., Oatis, B., Funk, J. A., Nash, A. J., Carrier, R. L., and
Hoyt, K. R. (2007). Metformin therapy in a transgenic mouse model of Huntington's disease. Neurosci. Lett. 411, 98-103.

Mai, A., Valente, S., Meade, S., Carafa, V., Tardugno, M., Nebbioso, A., Galmozzi, A., Mitro, N., De Fabiani, E., Altucci, L., and Kazantsev, A. (2009). Study of 1,4-dihydropyridine structural scaffold: discovery of novel sirtuin activators and inhibitors. $J$. Med. Chem. 52, 5496-5504.

Maxwell, M. M., Tomkinson, E. M. Nobles, J., Wizeman, J. W., Amore, A M., Quinti, L., Chopra, V., Hersch, S. M., and Kazantsev, A. G. (2011). The Sirtuin 2 microtubule deacetylase is an abundant neuronal protein that accumulates in the aging CNS. Hum. Mol. Genet. 20, 3986-3996.

McElwee, J., Bubb, K., and Thomas, J. H. (2003). Transcriptional outputs of the Caenorhabditis elegans forkhead protein DAF-16. Aging Cell 2, 111-121.

Milne, J. C., Lambert, P. D., Schenk, S., Carney, D. P., Smith, J. J., Gagne, D. J., Jin, L., Boss, O., Perni, R. B., Vu, C. B., Bemis, J. E., Xie, R., Disch, J. S., Ng, P. Y., Nunes, J. J., Lynch, A. V., Yang, H., Galonek, H., Israelian, K., Choy, W., Iffland, A., Lavu, S. Medvedik, O., Sinclair, D. A., Olefsky, J. M., Jirousek, M. R., Elliott, P. J., and Westphal, C. H. (2007). Small molecule activators of SIRT 1 as therapeutics for the treatment of type 2 diabetes. Nature 450, 712-716.

Morley, J. F., Brignull, H. R., Weyers, J. J., and Morimoto, R. I. (2002). The threshold for polyglutamineexpansion protein aggregation and cellular toxicity is dynamic and influenced by aging in Caenorhabditis elegans. Proc. Natl. Acad. Sci. U.S.A. 16, 16

Murphy, C. T. (2006). The search for DAF-16/FOXO transcriptional targets: approaches and discoveries. Exp. Gerontol. 41, 910-921.

Murphy, C. T., Mccarroll, S. A. Bargmann, C. I., Fraser, A., Kamath, R. S., Ahringer, J., Li, H., and Kenyon, C. (2003). Genes that act downstream of DAF-16 to influence the lifespan of Caenorhabditis elegans. Nature 424, 277-283.

Narasimhan, S. D., Yen, K., and Tissenbaum, H. A. (2009). Converging pathways in lifespan regulation. Curr. Biol. 19, R657-R666.

Oh, S. W., Mukhopadhyay, A., Dixit, B. L., Raha, T., Green, M. R., and Tissenbaum, H. A. (2006). Identification of direct DAF-16 targets controlling longevity, metabolism and diapause by chromatin immunoprecipitation. Nat. Genet. 38, 251-257.
Outeiro, T. F., Kontopoulos, E., Altmann, S. M., Kufareva, I., Strathearn, K. E., Amore, A. M., Volk, C. B., Maxwell, M. M., Rochet, J. C., Mclean, P. J., Young, A. B., Abagyan, R., Feany, M. B., Hyman, B. T., and Kazantsev, A. G. (2007). Sirtuin 2 inhibitors rescue alphasynuclein-mediated toxicity in models of Parkinson's disease. Science 317, 516-519.

Pacholec, M., Bleasdale, J. E., Chrunyk, B., Cunningham, D., Flynn, D. Garofalo, R. S., Griffith, D., Griffor, M., Loulakis, P., Pabst, B., Qiu, X., Stockman, B., Thanabal, V., Varghese, A., Ward, J., Withka, J., and Ahn, K. (2010). SRT1720, SRT2183, SRT1460, and resveratrol are not direct activators of SIRT1. J. Biol. Chem. 285, 8340-8351.

Paik, J. H., Ding, Z., Narurkar, R., Ramkissoon, S., Muller, F., Kamoun, W. S., Chae, S. S., Zheng, H., Ying, H., Mahoney, J., Hiller, D., Jiang, S., Protopopov, A., Wong, W. H., Chin, L., Ligon, K. L., and Depinho, R. A. (2009). FoxOs cooperatively regulate diverse pathways governing neural stem cell homeostasis. Cell Stem Cell 5, 540-553.

Pallos, J., Bodai, L., Lukacsovich, T., Purcell, J. M., Steffan, J. S., Thompson, L. M., and Marsh, J. L. (2008). Inhibition of specific HDACs and sirtuins suppresses pathogenesis in a Drosophila model of Huntington's disease. Hum. Mol. Genet. 17, 3767-3775.

Parker, J. A., Arango, M., Abderrahmane, S., Lambert, E., Tourette, C. Catoire, H., and Neri, C. (2005). Resveratrol rescues mutant polyglutamine cytotoxicity in nematode and mammalian neurons. Nat. Genet.37, 349-350.

Parker, J. A., Connolly, J. B., Wellington, C., Hayden, M., Dausset, J., and Neri, C. (2001). Expanded polyglutamines in Caenorhabditis elegans cause axonal abnormalities and severe dysfunction of PLM mechanosensory neurons without cell death. Proc. Natl. Acad. Sci. U.S.A. 98, 13318-13323.

Pasco, M. Y., Rotili, D., Altucci, L., Farina, F., Rouleau, G. A., Mai, A. and Neri, C. (2010). Characterization of sirtuin inhibitors in nematodes expressing a muscular dystrophy protein reveals muscle cell and behavioral protection by specific sirtinol analogues. J. Med. Chem. 53, 1407-1411.

Patel, K. R., Scott, E., Brown, V. A., Gescher, A. J., Steward, W. P., and Brown, K. (2011). Clinical trials of 
resveratrol. Ann. N. Y. Acad. Sci. 1215, 161-169.

Ramadori, G., Fujikawa, T., Anderson, J., Berglund, E. D., Frazao, R., Michan, S., Vianna, C. R., Sinclair, D. A., Elias, C. F., and Coppari, R. (2011). SIRT1 deacetylase in SF1 neurons protects against metabolic imbalance. Cell Metab. 14, 301-312.

Ramadori, G., Fujikawa, T., Fukuda, M., Anderson, J., Morgan, D. A., Mostoslavsky, R., Stuart, R. C., Perello, M., Vianna, C. R., Nillni, E. A., Rahmouni, K., and Coppari, R. (2010). SIRT1 deacetylase in POMC neurons is required for homeostatic defenses against diet-induced obesity. Cell Metab. 12, 78-87.

Rand, J. B., and Johnson, C. D. (1995). Genetic pharmacology: interactions between drugs and gene products in Caenorhabditis elegans. Methods Cell Biol. 48, 187-204.

Renault, V. M., Rafalski, V. A., Morgan, A. A., Salih, D. A., Brett, J. O., Webb, A. E., Villeda, S. A., Thekkat, P. U., Guillerey, C., Denko, N. C., Palmer, T. D., Butte, A. J., and Brunet, A. (2009). FoxO3 regulates neural stem cell homeostasis. Cell Stem Cell 5, 527-539.

Richard, T., Pawlus, A. D., Iglesias, M. L., Pedrot, E., Waffo-Teguo, P., Merillon, J. M., and Monti, J. P. (2011). Neuroprotective properties of resveratrol and derivatives. Ann. N. Y. Acad. Sci. $1215,103-108$

Rizki, G., Iwata, T. N., Li, J., Riedel, C. G., Picard, C. L., Jan, M., Murphy, C. T., and Lee, S. S. (2011). The evolutionarily conserved longevity determinants HCF-1 and SIR-2.1/SIRT1 collaborate to regulate DAF16/FOXO. PLoS Genet. 7, e1002235. doi:10.1371/journal.pgen.1002235

Schuff, M., Siegel, D., Bardine, N., Oswald, F., Donow, C., and Knochel, W. (2010). FoxO genes are dispensable during gastrulation but required for late embryogenesis in Xenopus laevis. Dev. Biol. 337, 259-273.

Schuster, E., Mcelwee, J. J., Tullet, J. M., Doonan, R., Matthijssens, F., ReeceHoyes, J. S., Hope, I. A., Vanfleteren, J. R., Thornton, J. M., and Gems, D. (2010). DamID in C. elegans reveals longevity-associated targets of DAF-16/FoxO. Mol. Syst. Biol. 6, 399.

Siegrist, S. E., Haque, N. S., Chen, C. H., Hay, B. A., and Hariharan, I. K. (2010). Inactivation of both Foxo and reaper promotes long-term adult neurogenesis in Drosophila. Curr. Biol. 20, 643-648.

Smith, J. J., Kenney, R. D., Gagne, D. J., Frushour, B. P., Ladd, W., Galonek, H. L., Israelian, K., Song, J., Razvadauskaite, G., Lynch, A. V., Carney, D. P., Johnson, R. J., Lavu, S., Iffland, A., Elliott, P. J., Lambert, P. D., Elliston, K. O., Jirousek, M. R., Milne, J. C., and Boss, O. (2009). Small molecule activators of SIRT1 replicate signaling pathways triggered by calorie restriction in vivo. BMC Syst. Biol.3, 31. doi:10.1186/1752-0509-3-31

Soerensen, M., Dato, S., Christensen, K., Mcgue, M., Stevnsner, T., Bohr, V. A., and Christiansen, L. (2010). Replication of an association of variation in the FOXO3A gene with human longevity using both case-control and longitudinal data. Aging Cell 9, 1010-1017.

Steinberg, G. R., and Kemp, B. E. (2009). AMPK in health and disease. Physiol. Rev. 89, 1025-1078.

Taylor, D. M., Balabadra, U., Xiang, Z., Woodman, B., Meade, S., Amore, A., Maxwell, M. M., Reeves, S., Bates, G. P., Luthi-Carter, R., Lowden, P. A., and Kazantsev, A. G. (2011). A brainpermeable small molecule reduces neuronal cholesterol by inhibiting activity of sirtuin 2 deacetylase. ACS Chem. Biol. 6, 540-546.

Tissenbaum, H. A., and Guarente, L. (2001). Increased dosage of a sir-2 gene extends lifespan in
Caenorhabditis elegans. Nature 410 227-230.

Vingtdeux, V., Davies, P., Dickson, D. W., and Marambaud, P. (2011). AMPK is abnormally activated in tangle- and pre-tangle-bearing neurons in Alzheimer's disease and other tauopathies. Acta Neuropathol. 121, 337-349.

Viswanathan, M., and Guarente, L. (2011). Regulation of Caenorhabditis elegans lifespan by sir-2.1 transgenes. Nature 477 . doi:10.1038/nature 10440

Walker, F. O. (2007). Huntington's disease. Lancet 369, 218-228.

Wang, F., Chan, C. H., Chen, K., Guan, X., Lin, H. K., and Tong, Q. (2011). Deacetylation of FOXO3 by SIRT1 or SIRT2 leads to Skp2mediated FOXO3 ubiquitination and degradation. Oncogene. doi: 10.1038/onc.2011.347. [Epub ahead of print].

Wang, F., Nguyen, M., Qin, F. X., and Tong, Q. (2007). SIRT2 deacetylates FOXO3a in response to oxidative stress and caloric restriction. Aging Cell 6, 505-514.

Willcox, B. J., Donlon, T. A., He, Q., Chen, R., Grove, J. S., Yano, K., Masaki, K. H., Willcox, D. C., Rodriguez, B., and Curb, J. D. (2008). FOXO3A genotype is strongly associated with human longevity. Proc. Natl. Acad. Sci. U.S.A. 105, 13987-13992.

Wood, J. G., Rogina, B., Lavu, S., Howitz, K., Helfand, S. L., Tatar, M., and Sinclair, D. (2004). Sirtuin activators mimic caloric restriction and delay ageing in metazoans. Nature 430, 686-689.

Yen, K., Narasimhan, S. D., and Tissenbaum, H. A. (2011). DAF16/Forkhead box O transcription factor: many paths to a single Fork(head) in the road. Antioxid. Redox Signal. 14, 623-634.

Yu, R. X., Liu, J., True, N., and Wang, W. (2008). Identification of direct target genes using joint sequence and expression likelihood with application to DAF-16. PLoS ONE 3, e1821. doi:10.1371/journal.pone.0001821

Yuan, Z., Lehtinen, M. K., Merlo, P., Villen, J., Gygi, S., and Bonni, A. (2009). Regulation of neuronal cell death by MST1-FOXO1 signaling. $J$. Biol. Chem. 284, 11285-11292.

Zhao, Y., Yang, J., Liao, W., Liu, X., Zhang, H., Wang, S., Wang, D., Feng, J., Yu, L., and Zhu, W. G. (2010). Cytosolic FoxO1 is essential for the induction of autophagy and tumour suppressor activity. Nat. Cell Biol. 12, 665-675.

Zuccato, C., Valenza, M., and Cattaneo, E. (2010). Molecular mechanisms and potential therapeutical targets in Huntington's disease. Physiol. Rev. 90, 905-981.

Conflict of Interest Statement: The author declares that the research was conducted in the absence of any commercial or financial relationships that could be construed as a potential conflict of interest.

Received: 09 November 2011; paper pending published: 09 January 2012; accepted: 25 January 2012; published online: 17 February 2012.

Citation: Neri C (2012) Role and therapeutic potential of the pro-longevity factor FOXO and its regulators in neurodegenerative disease. Front. Pharmacol. 3:15. doi: 10.3389/fphar.2012.00015 This article was submitted to Frontiers in Experimental Pharmacology and Drug Discovery, a specialty of Frontiers in Pharmacology.

Copyright ( $(2012$ Neri. This is an openaccess article distributed under the terms of the Creative Commons Attribution Non Commercial License, which permits non-commercial use, distribution, and reproduction in other forums, provided the original authors and source are credited. 